\title{
Development and Test of a Solid Oxide Fuel Cell Subsystem with a Low Temperature Anode Off-gas Recirculation
}

\author{
Ro. Peters ${ }^{a}$, M. Engelbracht ${ }^{a}$, W. Tiedemann ${ }^{a}$, I. Hovena, R. Deja a, V. N. Nguyen a, L. Blum a, D. Stolten a,b \\ a Forschungszentrum Jülich GmbH, Institute of Energy and Climate Research (IEK), 52428 Jülich, Germany \\ ${ }^{b}$ Faculty of Mechanical Engineering, RWTH Aachen University, 52072 Aachen, Germany
}

\section{Introduction}

In recent years, several SOFC systems spanning a wide power range, from a few watts into the several hundred kilowatt range, have been developed and demonstrated. Most of these are operated with hydrocarbon-containing fuels, with methane favored. At the JÜLICH, an SOFC subsystem was built and operated. This subsystem consists of the well-established Integrated Module, combined with a low temperature off-gas recirculation loop. The off-gas recirculation loop has two general advantages. Firstly, part of the unconverted fuel at the outlet of the stack is returned to the stack inlet and reused during the operation. Secondly, a proportion of the electrochemically-produced steam is simultaneously recirculated and can be used for the steam reforming process.

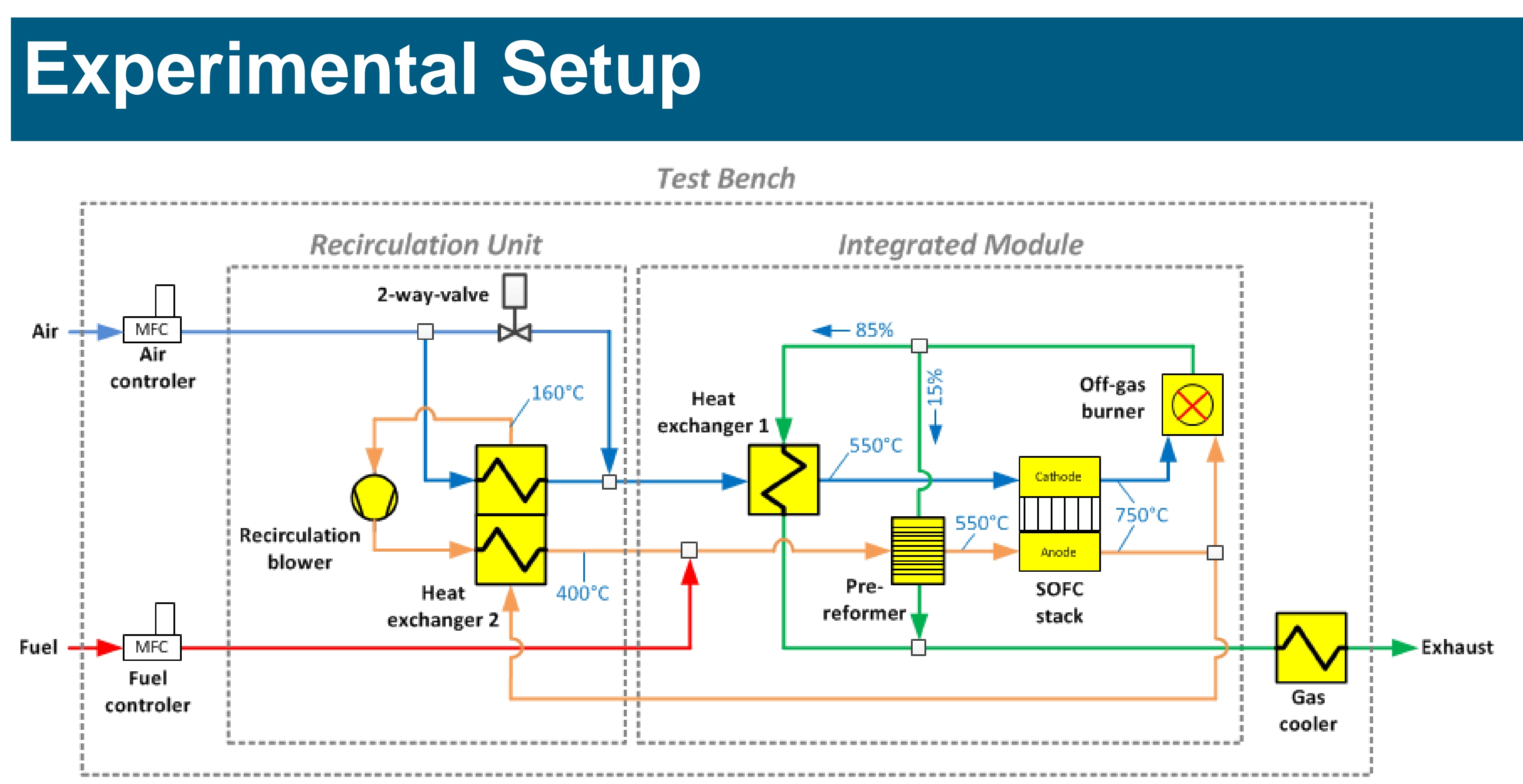

Fig. 1: Flow scheme of the SOFC subsystem

Within the test bench, almost the entire SOFC system is implemented, except air blower and power electronics.

Recirculation loop $\rightarrow$ The recirculated anode off-gas is cooled down in heat exchanger 2 using the cold anode offgas stream and the partial air stream. Thereby, the amount of air is controlled and adjusted to ensure a blower inlet temperature of approximately $160^{\circ} \mathrm{C}$. Downstream of the recirculation blower, the recirculate is reheated above $400^{\circ} \mathrm{C}$ with heat exchanger 2 .
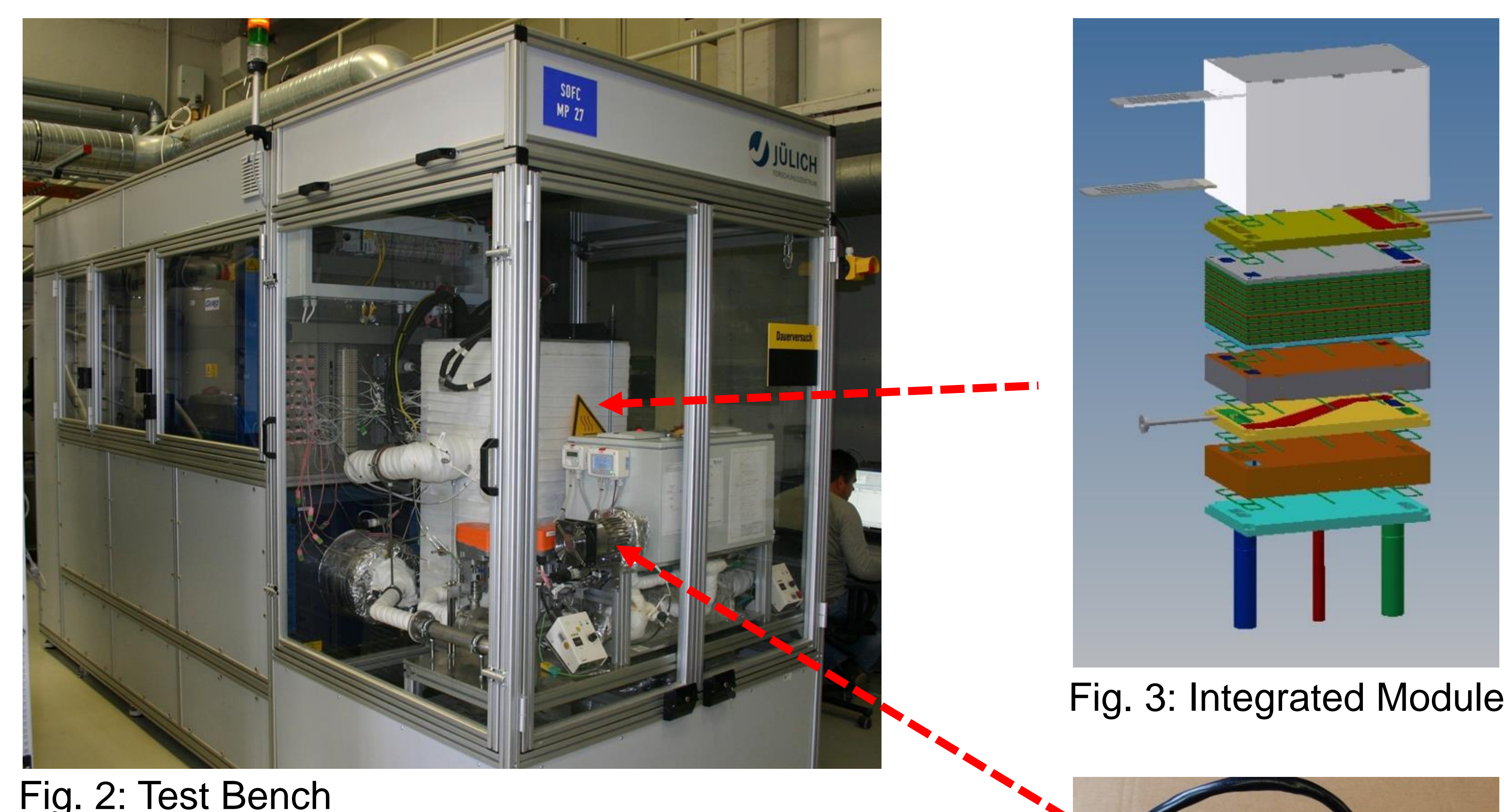

Fig. 3: Integrated Module

\begin{tabular}{|ll|}
\hline \multicolumn{2}{|l|}{ Boundary conditions of the system test. } \\
Cell Type & Anode Supported Cell \\
Cells per System & 36 \\
Active cell area & $0.0361 \mathrm{~m}^{2}$ \\
ASR at $750^{\circ} \mathrm{C}$ & $480 \mathrm{~m} \Omega / \mathrm{cm}^{2}$ \\
Test duration & $<2000 \mathrm{~h}$ \\
Pre-reformer catalyst & Nickel \\
Fuel & Methane \\
Recirculation blower & Side channel blower \\
\hline
\end{tabular}

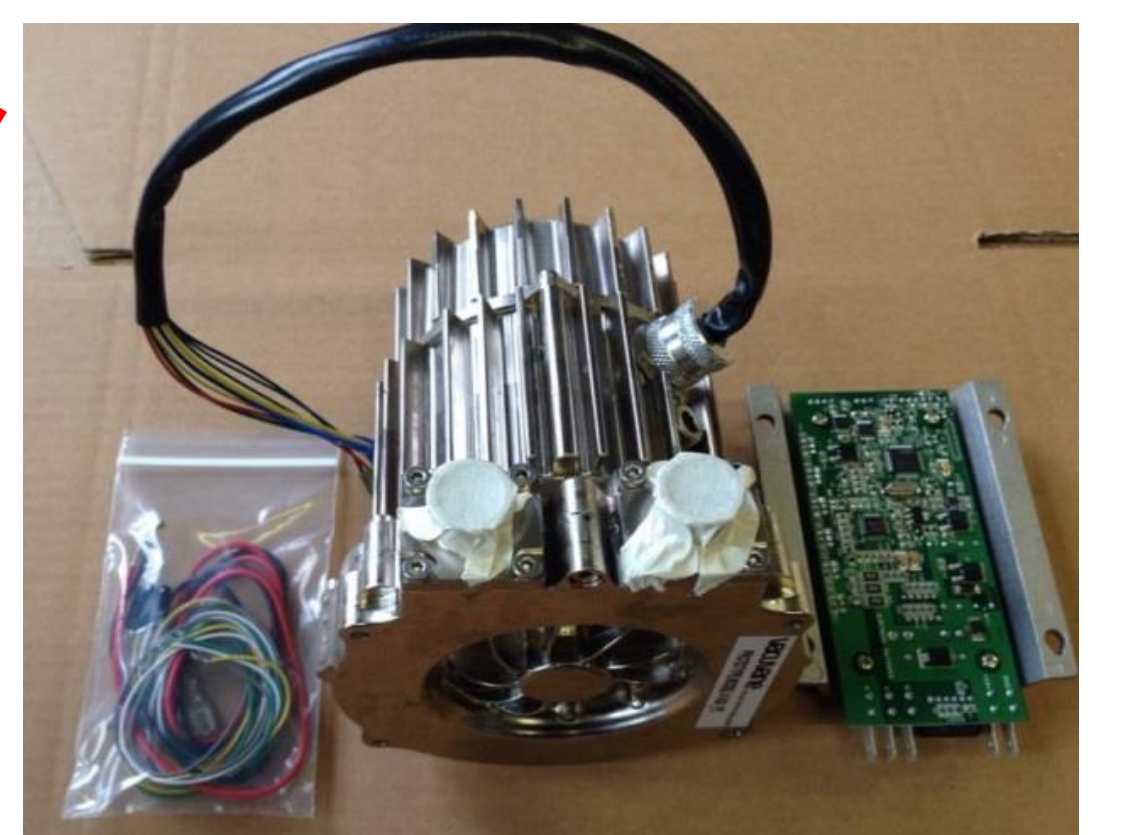

Fig.4: Side Channel Blower $\rightarrow$ Vacuvane $\mathrm{GmbH}$

\section{Results}

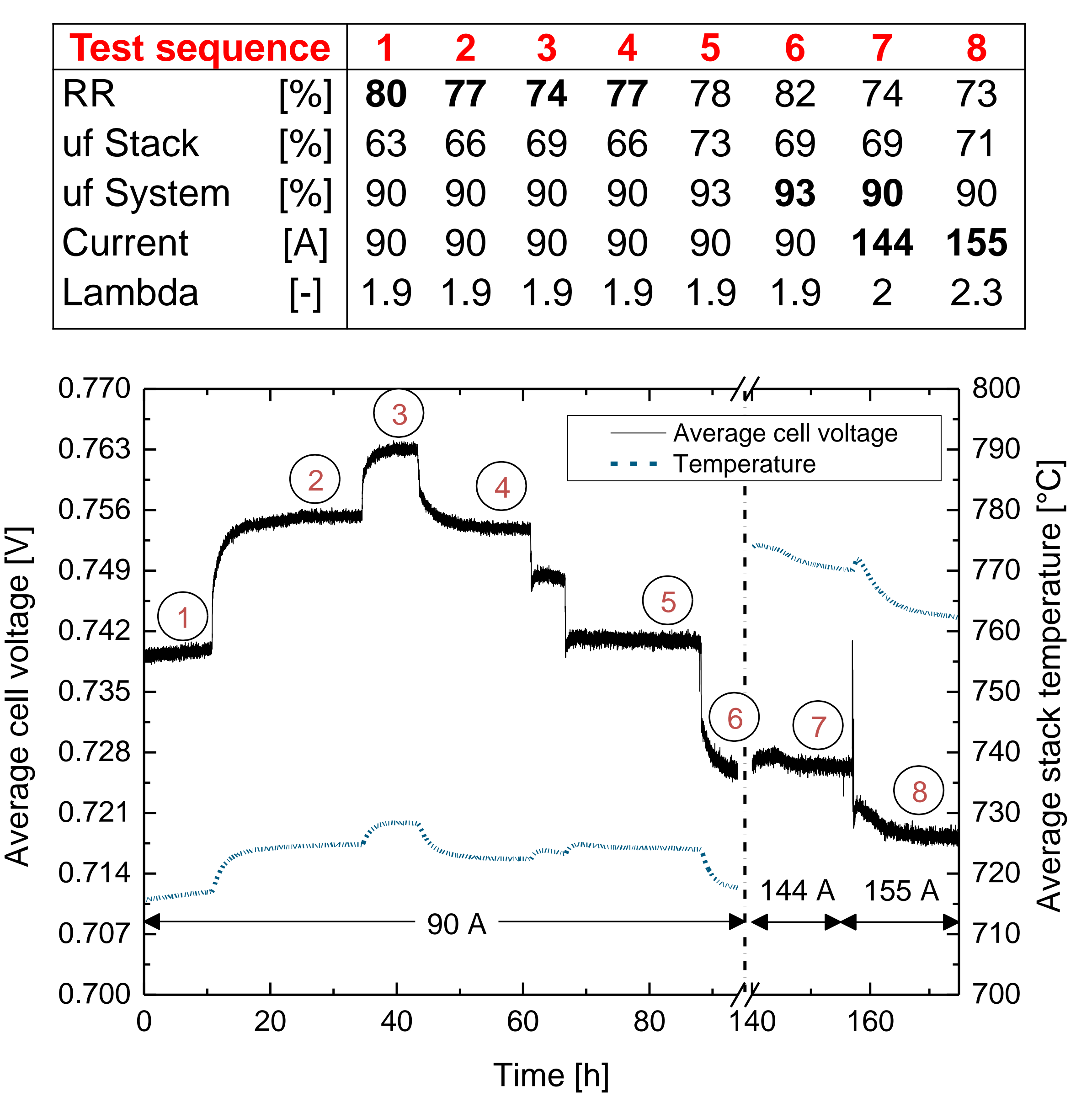

Fig. 5: Average cell voltage and temperature at 90, 144 and $155 \mathrm{~A}$ and different recirculation rates
The solid lines and dots represent the measured power output of the stack and the measured power demand of the recirculation blower. The dashed lines and open dots show the efficiency of a complete system, including the air blower (assumed efficiency, 27\%), the electrical power demand of the system (assumed with $50 \mathrm{~W}$ ) and inverter (assumed efficiency, 94\%).

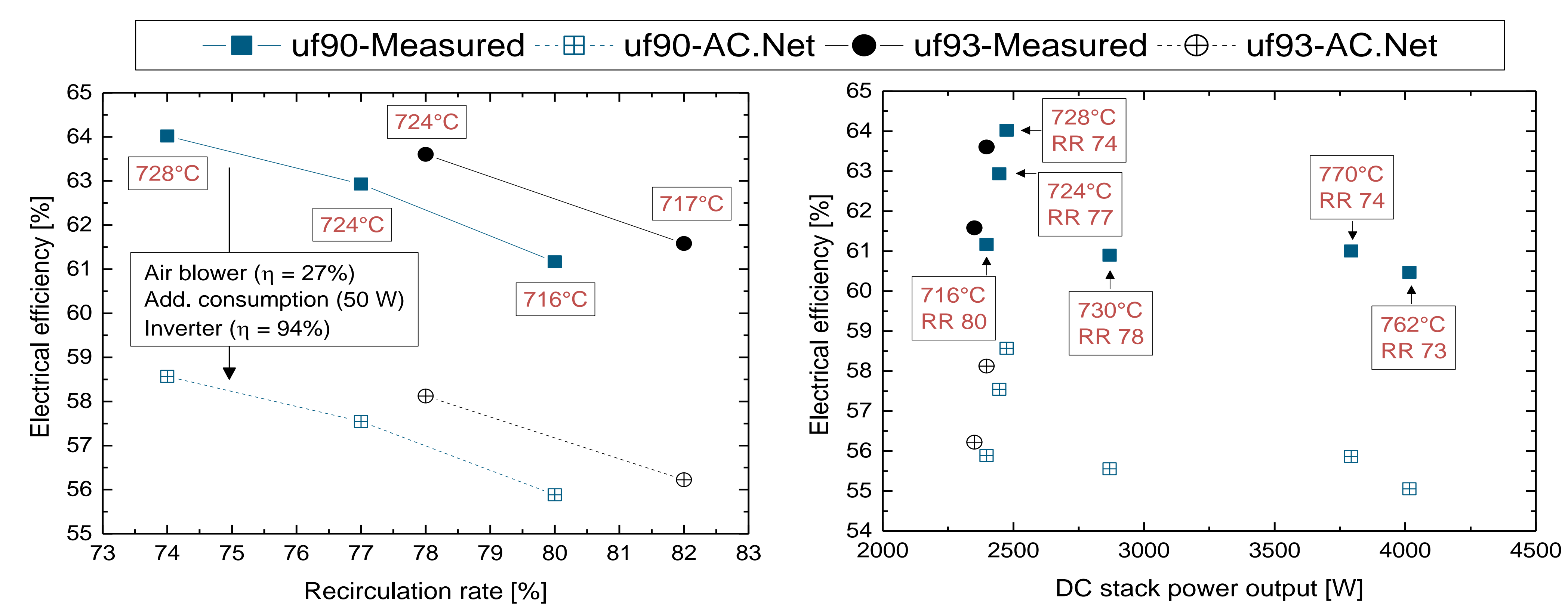

Fig. 6: Electrical efficiency at different recirculation rates and a current of $90 \mathrm{~A}$ (left) / electrical efficiency at different DC stack power output and recirculation rates (right)

\section{Conclusions}

- An anode off-gas recirculation in combination with JÜLICH's "Integrated Module" is realizable and successfully operated.

- High recirculation rates lead to a reduced cooling air demand of the stack (lambda <2).

- The stack can tolerate inlet gas temperatures of $500^{\circ} \mathrm{C}$ at anode side and $550^{\circ} \mathrm{C}$ at cathode side.

- The highest electrical efficiencies can be reached at high system fuel utilizations in combination with low recirculation rates.

- Electrical net efficiencies above $60 \%$ are achievable.

- The setup was up to $2.000 \mathrm{~h}$ in operation. 